\title{
BMJ Global Health Preparing international cooperation on pandemic prevention for the Anthropocene
}

\author{
Colin J Carlson (D , , Gregory F Albery, ${ }^{2}$ Alexandra Phelan ${ }^{1}$
}

To cite: Carlson CJ, Albery GF, Phelan A. Preparing international cooperation on pandemic prevention for the Anthropocene. BMJ Global Health

2021;6:e004254. doi:10.1136/ bmjgh-2020-004254

Handling editor Seye Abimbola

Received 20 0ctober 2020 Revised 19 February 2021 Accepted 21 February 2021

Check for updates

(C) Author(s) (or their employer(s)) 2021. Re-use permitted under CC BY-NC. No commercial re-use. See rights and permissions. Published by BMJ.

${ }^{1}$ Center for Global Health Science and Security, Georgetown University Medical Center, Washington, District of Columbia, USA

2Department of Biology, Georgetown University, Washington, District of Columbia, USA

Correspondence to

Colin J Carlson;

colin.carlson@georgetown.edu

\section{INTRODUCTION}

The COVID-19 pandemic has centred zoonotic viruses in nearly every discipline's efforts to reckon with modernity. This has been particularly highlighted in environmental policy, given the rise of paradigms like 'One Health' that centre the interconnectedness of human health and the environment, and that have given conservation organisations a seat at the table in global health. For those communities of practice, COVID-19 has underscored issues with the sustainability and safety of contact between humans and wildlife, and concerns about how unsustainable practices could contribute to the future emergence of novel coronaviruses or similar pandemic threats. ${ }^{1-3}$

More broadly, these conversations have pointed to a broader need to address the upstream drivers of poor health and disease burden outside of pandemic settings. In the One Health or planetary health tradition, pandemics can be viewed the product of several proximate drivers (eg, climate change, biodiversity loss, land degradation), all of which share an ultimate cause: the explosion of consumption, and destruction of the natural world, caused by capitalism, globalisation, colonialism and neoliberal economic policies. Insufficiently addressed by national and international policies to date (and, possibly, by proposed solutions for future sustainable growth), ${ }^{4}$ this process has pushed civilisation outside of a narrow zone that safely balances human well-being and economic growth against environmental preservation and long-term sustainability. ${ }^{56}$ This emerging view suggests that the most effective solutions may lie upstream in rethinking this model and addressing its failures across sectors, from carbon emissions to quality of life.

Even acknowledging the urgency of these societal transformations, we suggest that
Summary box

Anthropogenic stressors like climate change, land degradation, and wildlife trade are all risk factors for the future emergence of infectious diseases.

- Multilateral cooperation to reduce human footprints on natural systems will help reduce the spillover of emerging infections, but cannot necessarily prevent pandemics.

- Particularly given the fragility of international environmental cooperation, global health needs a strategy for pandemic prevention tailored to the Anthropocene.

- Future pandemic preparedness must include law and policy reform, health system strengthening, universal healthcare, and open and participatory science.

global health should carefully weigh the odds of successful risk reduction through upstream solutions, particularly in the near-term. To facilitate that analysis, we here review the most significant drivers of viral emergence, and the current state of international cooperative agreements that might produce meaningful transitions towards sustainability and reduced disease risk. Given current geopolitical challenges (especially in environmental policy), we contend that the sum of conservationreliant approaches will still be insufficient to prevent future public health emergencies. To adapt pandemic preparedness to the Anthropocene, policymakers must focus on multilateral cooperation to develop stronger and more equitable public health governance, to strengthen health systems for universal health coverage, and to adapt viral surveillance to the pressures of a changing world.

\section{SPILLOVER, PANDEMICS, AND GLOBAL CHANGE}

Due to early indications that SARS-CoV-2 originated in a wildlife market, the international wildlife trade has dominated recent conversations about future pandemic risk 
reduction. ${ }^{7-10}$ However, the hypothesis that the Huanan 'wet market' was the site of a spillover event has since been eliminated, with the market more likely a location of human to human transmission. ${ }^{11}$ Moreover, only a half-dozen of the hundreds of known zoonotic viruses have ever been linked to wildlife trade, ${ }^{12}$ while its predominance in policy discussions has been intertwined with racism and international tensions, especially Sinophobia. ${ }^{13-15}$ As a result, the predominance of wildlife trade in policy conversations-and the singulars urgency that predominantly Western conservation organisations have ascribed to these proposals-may have redirected attention away from bigger drivers of both spillover (like land degradation and climate change) and pandemics (like under-resourced public health and healthcare systems).

In the last few decades, land degradation and conversion has been the largest identifiable driver of emerging diseases. ${ }^{16}$ Humans are encroaching on wild land at an ever-increasing rate to support resource extraction, agricultural intensification, and urbanisation. As wild areas are destroyed and converted, encounters with displaced wildlife-often in poor health-create opportunities for zoonotic spillover. In rural areas, close proximity to livestock (and close proximity between livestock and wildlife) regularly exposes poor populations with potentially limited healthcare access to a number of zoonotic diseases. ${ }^{17}$ In human-dominated areas, wild species that survive land conversion are predisposed to high stress and weaker immune systems, ${ }^{18}$ reduced fear of humans, ${ }^{19}$ and ultimately, to hosting zoonotic pathogens. ${ }^{20}$ Together, these trends have driven a massive increase in infectious disease at the human-livestock-wildlife interface. ${ }^{21} 22$

In the near future, land use change is only likely to accelerate as urban environments and agricultural production track growing populations, and the compound effect of these changes will be compounded by the worsening reality of anthropogenic climate change. As the planet warms and species' current habitats become newly uninhabitable, animals will migrate to higher latitudes and higher elevations, profoundly reorganising the global ecosystem. ${ }^{23}{ }^{24}$ As species meet for the first time, they are projected to share viruses with each other thousands of times. ${ }^{25}$ Most cross-species transmission events will not affect human health, but a handful will include a mix of known threats, like Ebola virus (which could easily reach East African mammals in the next half-century); and unknown future threats, crossing into a new 'bridge host' that helps them reach humans (like civets for SARS-CoV, or camels for MERS-CoV).

Several features of this process exacerbate the potential risk for future pandemics. Flight could allow bats to easily cross continents, bringing many of the greatest zoonotic threats with them. Agricultural and human-settled areas will be hotspots of cross-species transmission, simply by virtue of their geography. ${ }^{25}$ Perhaps the biggest complication is a non-linearity in ecosystem responses to climate change: species' habitats will move furthest in extreme climate change scenarios, but species will be more able to track shifting habitats when the pace of environmental change is slower. As a result, scenarios with only small doses of climate change and land use change might produce the greatest ecological disruption, and policy solutions that target land conservation and greenhouse gas emissions are unlikely to prevent climate-linked zoonotic emergence.

In combination, it is reasonable to expect that climate change and land use could rapidly overtake other zoonotic drivers, like the wildlife trade or sustenance hunting, that have historically been the focus of blame for contributing excess 'pandemic risk'. In doing so, they will overturn a conventional view of the global balance of spillover risk, in which tropical rainforests sit at the intersection of undiscovered viral biodiversity, zoonotic drivers, human-wildlife contact and low outbreak preparedness. $^{26-29}$ Biodiversity hotspots facing rapid warming and accelerating deforestation, especially in southern China and southeast Asia, will face the greatest turnover of viral diversity. However, the rapid movement of species around the world also means that a pandemic-even one started by a virus that evolved in tropical rainforests-can easily begin anywhere.

Managing pandemic risk through surveillance-based aid programmes focused on Africa and Asia could therefore be an insufficient strategy as soon as the next decade. (Already, development assistance is inadequate for financing the investment necessary for pandemic preparedness, which - as the Global Preparedness Monitoring Board has recently noted-neglects the importance of social protection, such as policies to protect against the risks of unemployment, sickness and healthcare, parental and carer responsibilities, disability, old age and insecure housing. ${ }^{30}$ ) In its place, the world will need to shift to a model that better resembles pandemic influenza surveillance, which is based on rapidly identifying novel influenza subtypes globally, recognising that an influenza pandemic can start anywhere (as indeed the last one started somewhere in North America), and spread anywhere without the right countermeasures. ${ }^{31}$

\section{MITIGATION, ADAPTATION, AND PREDICTION}

The environmental sector is currently reimagining global governance by including pandemic risk in the dozens of interlinked and conflicting priorities that it already balances. Most efforts, again, have focused on wildlife markets and trade. China and Vietnam have both adopted national bans on wildlife trade, though these have implementation challenges and exemptions that risk weakening their zoonotic risk prevention, and similar bans have previously been repealed once political pressure waned. Revision of the Convention on International Trade in Endangered Species of Wild Fauna and Flora (CITES) to include provisions about zoonotic risk could expand this efficacy. ${ }^{32}$ Despite this focus, wildlife trade and consumption pathways have facilitated less than 
$10 \%$ of emerging zoonotic viruses (and an even smaller percent in international trade under CITES jurisdiction); efforts to replace wild meat protein through agricultural expansion and intensification may inadvertently increase environmental degradation, ${ }^{33}$ and potentially the spillover risk of livestock-associated viruses with pandemic potential, like influenza; and substantial concern remains that wildlife trade bans will "provide a cover for governments-and wider society-to say that action has been taken, without taking the action that is really needed'. ${ }^{34}$

At the same time, prospects to mitigate the global changes driving future zoonotic risk-the 'action that is really needed'-are equally not reassuring. The Paris Agreement to keep global warming under 1.5 degrees will undoubtedly save millions of lives, but noncompliance by the USA during the Trump presidency and insufficient commitment and implementation by other States currently jeopardises the achievability of the target, ${ }^{35}$ even now that the USA has returned under the Biden administration. Moreover, previous work has indicated that 1.5 degrees of warming is likely sufficient to unleash substantial viral turnover, ${ }^{25}$ and the world we live in today-roughly one degree warmer than preindustrial temperatures-may already be experiencing the widescale impacts of climate warming on zoonotic emergence.

Perhaps the most achievable option to reduce zoonotic disease emergence is sustainable development and land conservation, especially in bottom-up, locally-led contexts. ${ }^{36}$ This option is almost certainly the most cost effective for pandemic prevention: it might be two to 20 times more cost effective to halve deforestation in zoonotic hotspots than it would be to entirely end wildlife farming in China alone. ${ }^{8}$ Proposals like the 'half earth' conservation proposal are rapidly gaining traction as a solution to prevent the extinction crisis; ${ }^{38}{ }^{39}$ however, they face substantial challenges in terms of sovereignty (including on indigenous land), economic feasibility, agricultural land allocation and countries' willingness to participate at the expense of their economic growth. ${ }^{40} 41$

None of these proposals are sufficient to totally curb the spillover risk of novel pathogens. While they identify and target drivers that underlie an accelerating rate of viral emergence, none can singlehandedly address the growing human footprint on the planet, or its underlying causes. A more radical vision of international cooperation could be imagined as a systemic alternative, one that starts from first principles with human rights, sustainability and futurism over the increasingly unstable balancing act between capitalism and human well-being. This may well become the norm in the first half of the 21st century, particularly given closely related trends like antiracist movements, pressure to decolonise global health. or massive populist organising for climate action focused on holding corporate power accountable. This may even sway multinational governance; already, major platforms like the Intergovernmental Panel on Climate Change have called for 'rapid, far-reaching and unprecedented changes in all aspects of society'. ${ }^{42}$
But even with significant, transformative social change, viruses with pandemic potential will still exist, and have plenty of opportunities to cross the barriers between species (just as they did for centuries before the industrial revolution). Even with every available solution to minimise viral recombination in wildlife and excess contact between wildlife and humans, livestock and synanthropic wildlife (those that live comfortably alongside humans) in urban environments can still easily act as a bridge for the next pandemic virus. A strategy for the upcoming century that tries to prevent every pandemic at the source-even one that coordinates across environmental sectors-risks not only failing, but providing a false sense of security that undermines the necessary steps for pandemic preparedness.

\section{SAME AS IT EVER WAS}

Even with carefully tailored programmes to address global environmental change, outbreaks remain inevitable, but epidemics, and certainly pandemics, are not. Rather than lean into a worldview based in environmental determinism, where pandemics are the inevitable price of carbon emissions or deforestation, we suggest that global health already has tools to face a rising tide of emerging viruses. To borrow from the language of climate policy, the greatest global health governance need is a focus on 'adaptation' instead of 'mitigation': while ecological and economic solutions are necessarily devised to reduce upstream drivers of spillover risk, the global health community must prepare for the inevitability that spillover rates will still continue to growand must adapt to ensure that pandemic risk does not continue to grow commensurately. In any plausible future for climate change, global health and development, the world will have changed enough by 2050 that viruses cross between species thousands of times, many reaching humans for the first time. An Anthropoceneready health system must assume that inevitability, and prepare for both known and novel hazards.

Many of the core pillars of pandemic prevention remain consistent with pre-COVID-19 understanding: strong and responsive public health systems, including indicator and event-based surveillance systems and laboratory capabilities; well-resourced and trained healthcare workforce; and available, accessible, acceptable and quality healthcare. However, as the COVID-19 pandemic has demonstrated, good governance is a critical but overlooked component of pandemic preparedness: information received must be used to inform and rapidly mobilise public health response. This requires clearly defined laws and policies for governance, alongside decision-making that is accountable, transparent, equitable, participatory and consistent with the rule of law. ${ }^{43}$

Multilateral cooperation for pandemic preparedness is already undergoing significant review in light of the pandemic. This includes review of the International Health Regulations (2005) (IHR), the primary 
instrument to prevent and respond to the international spread of global health threats. While the IHR have been drafted to capture a range of threats to global health, the six public health emergencies of international concern declared have all been for specific virus epidemics (influenza A H1N1 (2009), wildtype poliovirus (2014), Ebola virus (2014), Zika virus (2016), Ebola virus (2019), SARS-CoV-2 (2020)). In addition, the IHR do not provide sufficient guidance to states for 'response' activities. At present, there are no indications that any potential revisions of the IHR will include substantive consideration of environmental issues like land use and climate change. The cochair of the WHO's newly established Independent Panel for Pandemic Preparedness and Response, Helen Clark, has referred to a potential international convention for pandemics, ${ }^{44}$ with the President of the European Council calling for a Pandemic Treaty under the auspices of the WHO. If appropriately situated, such as with the UN General Assembly, such a treaty could go beyond solely health expertise for pandemic preparedness and response, and include environmental, economic and social protection considerations. This could provide a synthesised and systematic preparedness and response framework for 21st century threats to health.

Similarly, the latest report of the Global Preparedness Monitoring Board released in September 2020 calls on United Nations leadership to agree to an international framework for health emergency preparedness, that incorporates the IHR and mechanisms for 'research and development, social protection, equitable access to countermeasures for all, and mutual accountability'. ${ }^{30}$ Whether reform to the IHR, or a potential new pandemic convention, or both, multilateralism for pandemic preparedness must expressly consider the postpandemic Anthropocene we live in and face. This includes tackling the fragmentation that has occurred between global health and the environment in practice, in international institutions, and in legal instruments. Across fields, this may also be an opportunity to improve governance reporting of health hazards, such as notification and data sharing obligations.

While improvements in governance may enable more rapid response, reducing the human toll of epidemics and especially pandemics depends more on strengthening human health systems. To that, ensuring universal healthcare (UHC) is a critical element of both pandemic preparedness and adaptation to a changing world. ${ }^{45}$ While there are a range of components to achieving UHC, strengthening primary healthcare can address $80 \%-90 \%$ of a person's health needs over their life, contributing to healthier populations and ensuring access to preventative care and treatment for acute and chronic conditions. ${ }^{46} \mathrm{UHC}$ is founded in the realisation of the right to health, and on the principles of ensuring that healthcare is available, accessible, acceptable and of sufficient quality, without discrimination. ${ }^{47}$ For pandemic preparedness, UHC ensures that when people are sick, they can access healthcare immediately, without fear of economic hardship, while building the trust and preventive healthcare necessary for public health. ${ }^{48}$ New evidence also suggests that in doing so, universal health coverage is also likely to improve conservation outcomes, and therefore reduce environmental degradation, in the communities where spillover risk is highest. ${ }^{49}$

Addressing injustice within (and in some cases caused by) the healthcare system is critical to addressing the disproportionate burden of epidemic diseases on already vulnerable populations. Not only does realising UHC contribute to strengthening health systems for epidemic disease, it prevents illness and death from a range of non-securitized health challenges, including maternal and child health, non-communicable diseases and injuries. It is critical that any multilateral or global efforts for a postpandemic recovery focus on the precise preparedness necessary to alleviate human suffering and prevent deaths from viruses and other health hazards.

Finally, these core aspects of pandemic preparedness can be supplemented by a modern vision of scientific research on zoonotic viruses rooted in international scientific cooperation. In the next decade, it might become possible to predict the zoonotic potential of a wildlife virus based on genomic, transcriptomic and structural data alone. ${ }^{50}$ Doing so would make the most of existing data on wildlife viruses, but conversely, might also require a shift to an open data model in wildlife virology that supports the development of the 'big data' needed for computational advances. ${ }^{51}$ Working to get existing data sets published-and focusing future surveillance on wildlife as they track shifting habitats, crossing national borders and bringing viruses to new places-will help virologists keep pace with both global change and the growing demands of public health and pandemic prevention.

Similar challenges exist for governance and accountability for equity in the sharing of pathogens, and epidemiological, clinical and genetic sequence data during outbreaks. ${ }^{52}$ The fragmentation of multilateral efforts to respond to significant issues of colonial resource exploitation between international environmental law and global health, risks undermining the importance of rapid and comprehensive data sharing while redressing the inequity of parachute research conducted for public health surveillance and response. To shift scientific culture as part of efforts to decolonise global health and the environment will likely need a parallel movement in how States are expected to share data, engage with scientists, and notify the international community about potential zoonotic risk before the first outbreak begins. In that light, this effort can be an opportunity for instilling not only collaboration but greater equity in our post-COVID-pandemic, pre-nextpandemic world. 


\section{CONCLUSIONS}

Global interest in COVID-19 is likely to foster creative solutions to reduce future pandemic risk, but an overt focus on prevention over preparedness is likely to leave global health weaker than before. This outcome is particularly likely if solutions embraced by the health security community fall into their characteristically reactive paradigm, focusing on the most recent spillover interface or ecological driver of relevance, rather than addressing the systemic tendency towards increased risk of viral emergence. In doing so, these directions may broadly undercut global health beyond pandemic preparedness. Global health practitioners and advocates have long fought to centre the addressing of inequality, the realisation of human rights and the strengthening of health systems in political and financial decision-making. Despite best efforts, these objectives have historically been overshadowed by donor-driven securitisation narratives. There is a risk that in postpandemic efforts, these narratives will be redoubled-this time, supplemented by voices from other fields, who will likely be unfamiliar with the unintended consequences that securitisation can have, and how these consequences might jeopardise the mission of health for all and undermine current movements to decolonise global health.

To achieve pandemic preparedness in the Anthropocene, policymakers must prioritise multilateral and multidisciplinary cooperation, paving the way for stronger and more equitable global health governance, health systems, and scientific research. That mission continues in parallel with efforts to stop climate change, to prevent the mass extinction of wild species and to live more sustainably alongside the reservoirs of future pandemic threats. Both missions are fragile, and could be jeopardised by growing tensions between the most powerful countries and the most vulnerable. While environmental action will reduce opportunities for the next pandemic, our ability to face it cannot be contingent on the success of these efforts. Global health must continue fighting to build 'health for all' into our understanding of the Anthropocene, and reject singular solutions to complex problems, or efforts that chase prevention at the expense of preparedness. Failure to do so risks diverting political attention and finances to solutions that-at a minimum-do not include the cobenefits of health systems strengthening, or-at worst-give a false sense of preparedness for the next pandemic.

\section{Acknowledgements The authors thank the Verena Consortium ( viralemergence.org) for formative conversations, especially Evan Eskew; and thank Christine Johnson and Peta Hitchens for sharing data on drivers of zoonotic emergence.}

Contributors All authors contributed to the writing and conception of the manuscript.

Funding CJC and GFA were supported by NSF BII 2021909 and the Institut de Valorisation des Données (IVAD0).

Competing interests None declared.
Patient consent for publication Not required.

Provenance and peer review Not commissioned; externally peer reviewed.

Data availability statement There are no data in this work.

Open access This is an open access article distributed in accordance with the Creative Commons Attribution Non Commercial (CC BY-NC 4.0) license, which permits others to distribute, remix, adapt, build upon this work non-commercially, and license their derivative works on different terms, provided the original work is properly cited, appropriate credit is given, any changes made indicated, and the use is non-commercial. See: http://creativecommons.org/licenses/by-nc/4.0/.

\section{ORCID iD}

Colin J Carlson http://orcid.org/0000-0001-6960-8434

\section{REFERENCES}

1 Guerriero C, Haines A, Pagano M. Health and sustainability in postpandemic economic policies. Nat Sustain 2020;3:494-6.

2 Roche B, Garchitorena A, Guégan J-F, et al. Was the COVID-19 pandemic avoidable? A call for a "solution-oriented" approach in pathogen evolutionary ecology to prevent future outbreaks. Ecol Lett 2020;23:1557-60.

3 Shreedhar G, Mourato S. Linking human destruction of nature to COVID-19 increases support for wildlife conservation policies. Environ Resour Econ 2020:1-37.

4 Hickel J, Kallis G. Is green growth possible? New Political Economy 2020;25:469-86.

5 Hickel J. Is it possible to achieve a good life for all within planetary boundaries? Third World Q 2019;40:18-35.

6 Raworth K. A Doughnut for the Anthropocene: humanity's compass in the 21st century. Lancet Planet Health 2017;1:e48-9.

7 Aguirre AA, Catherina $\mathrm{R}$, Frye $\mathrm{H}$, et al. Illicit wildlife trade, wet markets, and COVID-19: preventing future pandemics. World Med Health Policy 2020;12:256-65.

8 Dobson AP, Pimm SL, Hannah L, et al. Ecology and economics for pandemic prevention. Science 2020;369:379-81.

9 Editorial. Exploring wet markets. Nat Food 2020;1:241

10 Mallapaty S. Scientists call for pandemic investigations to focus on wildlife trade. Nature 2020;583:344.

11 Areddy JT. China rules out animal market and lab as coronavirus origin. Wall Street Journal 2020 https://www.wsj.com/articles/ china-rules-out-animal-market-and-lab-as-coronavirus-origin11590517508

12 Kreuder Johnson C, Hitchens PL, Smiley Evans T, et al. Spillover and pandemic properties of zoonotic viruses with high host plasticity. Sci Rep 2015;5:14830.

13 Margulies JD, Wong RWY, Duffy R. The imaginary 'Asian Super Consumer': A critique of demand reduction campaigns for the illegal wildlife trade. Geoforum 2019;107:216-9.

14 Eskew EA, Carlson CJ. Overselling wildlife trade bans will not bolster conservation or pandemic preparedness. Lancet Planet Health 2020;4:e215-6.

15 Roe D, Dickman A, Kock R, et al. Beyond banning wildlife trade: COVID-19, conservation and development. World Dev 2020;136:105121.

16 Loh EH, Zambrana-Torrelio C, Olival KJ, et al. Targeting transmission pathways for emerging zoonotic disease surveillance and control. Vector Borne Zoonotic Dis 2015;15:432-7.

17 Grace D, Lindahl J, Wanyoike F, et al. Poor livestock keepers: ecosystem-poverty-health interactions. Philos Trans $R$ Soc Lond B Biol Sci 2017;372:20160166.

18 Werner CS, Nunn CL. Effect of urban habitat use on parasitism in mammals: a meta-analysis. Proc Biol Sci 2020;287:20200397.

19 Goumas M, Collins TR, Fordham L, et al. Herring gull aversion to gaze in urban and rural human settlements. Anim Behav 2020;168:83-8.

20 Gibb R, Redding DW, Chin KQ, et al. Zoonotic host diversity increases in human-dominated ecosystems. Nature 2020;584:398-402.

21 Jones KE, Patel NG, Levy MA, et al. Global trends in emerging infectious diseases. Nature 2008;451:990-3.

22 Smith KF, Goldberg M, Rosenthal S, et al. Global rise in human infectious disease outbreaks. J R Soc Interface 2014;11:20140950.

23 Chen I-C, Hill JK, Ohlemüller R, et al. Rapid range shifts of species associated with high levels of climate warming. Science 2011;333:1024-6.

24 Trisos $\mathrm{CH}$, Merow C, Pigot AL. The projected timing of abrupt ecological disruption from climate change. Nature 2020;580:496-501. 
25 Carlson CJ, Albery GF, Merow C. Climate change will drive novel cross-species viral transmission. bioRxiv 2020.

26 Allen T, Murray KA, Zambrana-Torrelio C, et al. Global hotspots and correlates of emerging zoonotic diseases. Nat Commun 2017;8:1124.

27 Olival KJ, Hosseini PR, Zambrana-Torrelio C, et al. Host and viral traits predict zoonotic spillover from mammals. Nature 2017;546:646-50

28 Oppenheim B, Gallivan M, Madhav NK, et al. Assessing global preparedness for the next pandemic: development and application of an epidemic preparedness index. BMJ Glob Health 2019;4:e001157.

29 Morand S. Emerging diseases, livestock expansion and biodiversity loss are positively related at global scale. Biol Conserv 2020;248:108707.

30 Global Preparedness Monitoring Board. A World in Disorder. Global Preparedness Monitoring Board Annual Report 2020 [Internet]. World Health Organization, 2020. Available: https://apps.who.int/ gpmb/assets/annual_report/GPMB_AR_2020_EN.pdf

31 Barry JM. The site of origin of the 1918 influenza pandemic and its public health implications. J Trans/ Med 2004;2:3.

32 Weissgold BJ, Knights P, Lieberman S. How we can use the CITES wildlife trade agreement to help prevent pandemics.. Sci Am 2020 https://www.scientificamerican.com/article/how-we-can-use-thecites-wildlife-trade-agreement-to-help-prevent-pandemics/

33 Booth H, Clark M, Milner-Gulland EJ, et al. Investigating the risks of removing wild meat from global food systems. Current Biology 2021;367.

34 Roe D, Lee TM. Possible negative consequences of a wildlife trade ban. Nat Sustain 2021;4:5-6.

35 United Nations Environment Programme. Emissions gap report 209. UNEP, 2019. Available: https://wedocs.unep.org/bitstream/handle/ 20.500.11822/30797/EGR2019.pdf?sequence=1\&isAllowed=y

36 Gibb R, Franklinos LHV, Redding DW, et al. Ecosystem perspectives are needed to manage zoonotic risks in a changing climate. BMJ 2020;371:m3389.

37 Plowright RK, Reaser JK, Locke H, et al. Land use-induced spillover: a call to action to safeguard environmental, animal, and human health. Lancet Planet Health 2021. doi:10.1016/S25425196(21)00031-0. [Epub ahead of print: 05 Mar 2021].

38 Pimm SL, Jenkins CN, Li BV. How to protect half of earth to ensure it protects sufficient biodiversity. Sci Adv 2018;4:eaat2616.

39 Hannah L, Roehrdanz PR, Marquet PA, et al. 30\% land conservation and climate action reduces tropical extinction risk by more than 50\%. Ecography 2020;43:943-53.
40 Kopnina $\mathrm{H}$. Half the earth for people (or more)? addressing ethical questions in conservation. Biol Conserv 2016;203:176-85.

41 Ellis EC, Mehrabi Z. Half Earth: promises, pitfalls, and prospects of dedicating Half of Earth's land to conservation. Current Opinion in Sustain 2019;38:22-30.

42 Intergovernmental Panel on Climate Change. Global warming of $1.5^{\circ} \mathrm{C}$. An IPCC special report on the impacts of global warming of $1.5^{\circ} \mathrm{C}$ above pre-industrial levels and related global greenhouse gas emission pathways, in the context of strengthening the global response to the threat of climate change, sustainable development, and efforts to eradicate poverty. IPCC, 2018. Available: https://www. ipcc.ch/sr15/

43 Phelan A, Katz R. Governance preparedness: initial lessons from COVID-19. background report for the global preparedness monitoring board. center for global health science and security, 2020. Available: https://apps.who.int/gpmb/assets/thematic papers_2020/tp_2020_1.pdf

44 Roy EA. Helen Clark: WHO coronavirus inquiry aims to "stop the world being blindsided again". The Guardian, 2020. Available: https://www.theguardian.com/world/2020/jul/10/helen-clark-whocoronavirus-inquiry-aims-to-stop-the-world-being-blindsidedagain

45 Phillips CA, Caldas A, Cleetus R, et al. Compound climate risks in the COVID-19 pandemic. Nat Clim Chang 2020;10:586-8.

46 The Lancet .The Astana declaration: the future of primary health care? Lancet 2018;392:1369.

47 Nygren-Krug $\mathrm{H}$. The right(s) road to universal health coverage. Health Hum Rights 2019;21:215.

48 World Health Organization. Making fair choices on the path to universal health coverage: final report of the who consultative group on equity and universal health coverage. World Health organization, 2014. Available: https://apps.who.int/iris/bitstream/handle/10665/ 112671/9789241507158_eng.pdf;jsessionid=7EAA48818A5C8B88 513AF0E1C8DABF68? sequence $=1$

49 Jones IJ, MacDonald AJ, Hopkins SR, et al. Improving rural health care reduces illegal logging and conserves carbon in a tropical forest. Proc Natl Acad Sci U S A 2020;117:28515-24.

50 Mollentze N, Babayan SA, Streicker DG. Identifying and prioritizing potential human-infecting viruses from their genome sequences. bioRxiv 2021.

51 Carlson CJ. From predict to prevention, one pandemic later. Lancet Microbe 2020;1:e6-7.

52 Rourke M, Eccleston-Turner M, Phelan A, et al. Policy opportunities to enhance sharing for pandemic research. Science $2020 ; 368: 716-8$. 